\title{
Use of Spectroscopic Techniques for a Rapid and Non-Destructive Monitoring of Thermal Treatments and Storage Time of Sous-Vide Cooked Cod Fillets
}

\author{
Abdo Hassoun ${ }^{1, *(D)}$, Janna Cropotova ${ }^{2}$, Turid Rustad ${ }^{2}$, Karsten Heia ${ }^{1}$, Stein-Kato Lindberg ${ }^{1}$ \\ and Heidi Nilsen ${ }^{1}$ \\ 1 Nofima, Norwegian Institute of Food, Fisheries, and Aquaculture Research, Muninbakken 9-13, \\ 9291 Tromsø, Norway; karsten.heia@nofima.no (K.H.); stein-kato.lindberg@nofima.no (S.-K.L.); \\ heidi.nilsen@nofima.no (H.N.) \\ 2 Department of Biotechnology and Food Science, Norwegian University of Science and Technology, \\ 7941 Trondheim, Norway; janna.cropotova@ntnu.no (J.C.); turid.rustad@ntnu.no (T.R.) \\ * Correspondence: abdo.hassoun@nofima.no
}

Received: 30 March 2020; Accepted: 22 April 2020; Published: 23 April 2020

\begin{abstract}
In this work, the potential of spectroscopic techniques was studied to investigate heat-induced changes occurring during the application of thermal treatments on cod (Gadus morhua L.) fillets. Vacuum-packed samples were thermally treated in a water bath at 50, 60, 70 and $80^{\circ} \mathrm{C}$ for 5 and $10 \mathrm{~min}$, and further stored for one, four, and eight days at $4 \pm 1^{\circ} \mathrm{C}$ before analysis. Several traditional (including cooking loss, drip loss, texture, protein solubility, protein oxidation, and color) and spectroscopic (fluorescence and diffuse reflectance hyperspectral imaging) measurements were conducted on the same samples. The results showed a decrease in fluorescence intensity with increasing cooking temperature and storage time, while the impact of cooking time was only noticeable at low temperatures. Diffuse reflectance data exhibited a decrease in absorbance, possibly as a result of protein denaturation and increased scattering at higher cooking temperatures. Both fluorescence and diffuse reflectance data were highly correlated with color parameters, whereas moderate correlations were observed with most other traditional parameters. Support vector machine models performed better than partial least square ones for both classification of cod samples cooked at different temperatures and in prediction of the cooking temperature. The best classification result was obtained on fluorescence data, achieving an accuracy of $92.5 \%$, while the prediction models resulted in a root mean square error of prediction of cooking temperature lower than $5{ }^{\circ} \mathrm{C}$. Overall, the classification and prediction models showed good results, indicating that spectroscopic techniques, especially fluorescence hyperspectral imaging, have a high potential for monitoring thermal treatments in cod fillets.
\end{abstract}

Keywords: fish; fluorescence; cooking; classification; spectroscopy; storage; prediction

\section{Introduction}

The application of thermal treatments to food products has been widely used since ancient times with the purpose of destroying pathogens and giving the food desired organoleptic properties as well as increased digestibility. Nowadays, most foods, especially muscle foods (fish, meat, etc.), should be subjected to different types of thermal treatments during processing or preparation prior to consumption. A common practice in the food industry is to overheat food in order to ensure the safety of the processed products. However, the application of more heat than required causes an unnecessarily high energy consumption resulting in a lower profitability in the seafood industry [1]. Moreover, as fish and other seafood products are highly sensitive to thermal treatments, the application 
of severe heat can have negative consequences on sensory attributes, such as color, texture, etc., of the processed products. For example, some studies indicated that high temperatures can lead to protein and lipid oxidation as well as significant textural and structural modifications in seafood products [2-5]. Nutritional quality parameters (e.g., digestibility) are also affected by high thermal loads, for example, as in the case of heating fish at $200^{\circ} \mathrm{C}$ for an extended period of time $[6,7]$.

Thus, applying the appropriate amount of heating, just enough to kill pathogenic microorganisms, without affecting sensory and nutritional quality of the treated products is a challenging task. Optimization of the thermal processing requires both minimal heat processing in order to avoid undesired effects of high thermal load, and efficient analytical methods that allow for a rapid detection of heat-induced changes and eventual corrective actions, if necessary [8]. Several studies have investigated different minimal heat processing methods, and the results have varied both according to the raw material quality and the applied technique, among others [9-12]. Traditionally, heat-induced changes and quality of fish and other seafoods are evaluated using sensory, microbiological, and physio-chemical analysis, such as oxidation products, color, and texture $[5,13,14]$. For example, the texture is a key quality parameter of fish and other seafood, and has been widely evaluated using sensory and instrumental methods $[5,15,16]$. However, it is well known that measuring the texture of fish is a challenging task as texture parameters, such as hardness, change along the fish as a function of its thickness [17]. Besides the specific limitations associated with each traditional method (e.g., change in thickness when measuring the texture), a more general challenge with most of these methods is that they are destructive, thus cannot be used to evaluate all products, and only a few samples are analyzed offline. On the contrary, spectroscopic techniques can be used to scan samples at line, online, or inline of production. With at line scanning, the sample is withdrawn and analyzed in the immediate environment of the industrial equipment, while in the case of online measurements, a portion of the production is analyzed via a by-pass system, then it returns to the system. The ideal solution is the inline scanning where a sensor can be placed in a process stream of flowing material, thus all the production volume is analyzed.

Several studies have indicated that spectral changes induced by application of heat can be used to monitor thermal treatments in fish and other seafoods. Thus, the development of noncontact, non-destructive, and real-time measurement sensors based on spectroscopy can be a valuable tool in the modern food industry [8]. Previous studies have investigated the potential of visible and near infrared spectroscopy [1,8,11,12], Raman spectroscopy [18,19], and nuclear magnetic resonance (NMR) [4,20] for monitoring changes in seafood induced by the application of thermal treatments. However, only a few studies in literature have reported on the use of fluorescence spectroscopy for monitoring thermal treatments in fish and other seafood products. In the studies that have recently investigated the potential of fluorescence spectroscopy, the technique was mainly used as a complementary tool to support other results obtained from traditional measurements [7,21]. The combination of fluorescence with hyperspectral imaging makes it a promising tool for various applications in the food industry. Taking this into account, the main objective of this study is to evaluate the feasibility of using hyperspectral imaging in fluorescence mode to investigate changes in cod samples induced by heat and following chilled storage and to compare the results with diffuse reflectance spectroscopy and a selection of traditional analysis. The samples were evaluated packed while moving on a conveyor belt in order to mimic industrial processes.

\section{Materials and Methods}

\subsection{Samples Preparation and Cooking Treatment}

A Norwegian Arctic cod, labelled as "Skrei", was obtained from Vengsøya near Tromsø (in Norway), on the day of catch. The fish was gutted, iced, and transported to Nofima (Tromsø, Norway) the same day. The next day, the fish was filleted, and only the loin parts were used for the experiments. Each fish was cut into two fillets, and two loin-pieces (samples) were obtained from each fillet. One hundred and 
twenty samples were obtained from 3 batches of fish (Table 1). Twenty-four samples were analyzed on day 1, 4, and 8 without cooking (control group), with half of the samples being vacuum-packed and the other half being air packed. The rest of the fish (96 samples) were divided into 8 groups, each group of 12 samples. The samples were cooked at different temperatures $\left(50,60,70\right.$ or $\left.80{ }^{\circ} \mathrm{C}\right)$ for 5 or $10 \mathrm{~min}$. Before cooking, the samples were vacuum-packed and then cooked in a water bath preheated at the desired temperature. After cooking, the samples were cooled in iced water for 1 minute and analyzed on day 1 and stored at $4 \pm 1{ }^{\circ} \mathrm{C}$ for further analysis performed on days 4 and 8 . Four samples from each group and for each storage day were analyzed.

Table 1. Summary of the experimental design.

\begin{tabular}{|c|c|c|c|c|c|}
\hline Trea & ents & D1 & D4 & D8 & Total Number \\
\hline \multirow{2}{*}{ Control } & $\mathbf{V}$ & $\operatorname{D1TxtxV}(\mathrm{n}=4)$ & D4TxtxV $(\mathrm{n}=4)$ & D8TxtxV $(\mathrm{n}=4)$ & $\mathrm{n}=12$ \\
\hline & A & D1TxtxA $(\mathrm{n}=4)$ & D4TxtxA $(\mathrm{n}=4)$ & D8TxtxA $(\mathrm{n}=4)$ & $\mathrm{n}=12$ \\
\hline \multirow{2}{*}{ T50 } & $5 \mathrm{~min}$ & D1T50t5 $(\mathrm{n}=4)$ & D4T50t5 $(\mathrm{n}=4)$ & D8T50t5 $(\mathrm{n}=4)$ & $\mathrm{n}=12$ \\
\hline & $10 \mathrm{~min}$ & D1T50t10 $(\mathrm{n}=4)$ & D4T50t10 $(\mathrm{n}=4)$ & D8T50t10 $(\mathrm{n}=4)$ & $\mathrm{n}=12$ \\
\hline \multirow{2}{*}{ T60 } & $5 \mathrm{~min}$ & D1T60t5 $(\mathrm{n}=4)$ & D4T60t5 $(\mathrm{n}=4)$ & D8T60t5 $(\mathrm{n}=4)$ & $\mathrm{n}=12$ \\
\hline & $10 \mathrm{~min}$ & D1T60t10 $(\mathrm{n}=4)$ & D4T60t10 $(\mathrm{n}=4)$ & D8T60t10 $(\mathrm{n}=4)$ & $\mathrm{n}=12$ \\
\hline \multirow{2}{*}{ T70 } & $5 \mathrm{~min}$ & D1T70t5 $(\mathrm{n}=4)$ & D4T70t5 $(\mathrm{n}=4)$ & D8T70t5 $(\mathrm{n}=4)$ & $\mathrm{n}=12$ \\
\hline & $10 \mathrm{~min}$ & D1T70t10 $(\mathrm{n}=4)$ & D4T70t10 $(\mathrm{n}=4)$ & D8T70t10 $(\mathrm{n}=4)$ & $\mathrm{n}=12$ \\
\hline \multirow{2}{*}{ T80 } & $5 \mathrm{~min}$ & D1T80t5 $(\mathrm{n}=4)$ & D4T80t5 $(\mathrm{n}=4)$ & D8T80t5 $(\mathrm{n}=4)$ & $\mathrm{n}=12$ \\
\hline & $10 \mathrm{~min}$ & D1T80t10 $(\mathrm{n}=4)$ & D4T80t10 $(\mathrm{n}=4)$ & D8T80t10 $(\mathrm{n}=4)$ & $\mathrm{n}=12$ \\
\hline
\end{tabular}

D; storage days (D1, D4, D8), T; cooking temperature (T50, T60, T70, T80), t; cooking time (5 min, $10 \mathrm{~min})$,

V; vacuum-packed samples, A; air-packed samples. Total number of samples $=120$.

\subsection{Traditional and Spectroscopic Measurements}

Cooking loss was determined gravimetrically as the difference in weight of samples before and after the heat treatment (twelve replicates for each cooking temperature/time). The sous-vide cooked fish samples were removed from the vacuum bags and wiped gently with tissue paper to remove excess surface moisture before performing the measurements. The liquid remaining in the vacuum bag after taking out the fish was weighed and the drip loss was calculated as the percentage of fish weight loss after removing the liquid [22].

Texture profile analysis (TPA) was performed using the TA.HD plus texture analyzer (Stable Micro System) at room temperature. The test conditions were the following: two consecutive cycles of $80 \%$ compression using a flat-ended cylindrical plunger $(12 \mathrm{~mm}$ diameter), pre-test speed: $5 \mathrm{~mm} / \mathrm{s}$, test speed: $1 \mathrm{~mm} / \mathrm{s}$, post-test speed: $10 \mathrm{~mm} / \mathrm{s}$, target mode: strain, trigger force: $5 \mathrm{~g}$. The following TPA parameters were obtained from force-time curves: hardness, cohesiveness, springiness, chewiness, and resistance [16].

The solubility of sarcoplasmic (water-soluble) and myofibrillar (salt-soluble) proteins was determined according to the method described by Hultmann and Rustad (2002) [23]. Fish samples were ground with a benchtop mixer Bosch ( $750 \mathrm{~W}$, Germany) and $4 \mathrm{~g}$ were taken for further homogenization for $20 \mathrm{~s}$ in $80 \mathrm{~mL}$ phosphate buffer $(0.05 \mathrm{M}$ phosphate, $\mathrm{pH} 7.0)$ using an Ultra Turrax (samples were kept on ice $0+1{ }^{\circ} \mathrm{C}$ ) followed by centrifugation at $8000 \mathrm{~g}$ for $20 \mathrm{~min}$ ). The resulting volume was made up to $100 \mathrm{~mL}$ with phosphate buffer (water-soluble fraction). The remaining precipitate was further homogenized for $10 \mathrm{~s}$ in phosphate buffer with $\mathrm{KCl}(0.05 \mathrm{M}$ phosphate, $0.6 \mathrm{M} \mathrm{KCl}, 0.5 \%$ tritonX-405, pH 7.0), and centrifuged as described above. The supernatant was adjusted to $100 \mathrm{~mL}$ with KCl-phosphate buffer (salt-soluble fraction). The amount of proteins in the extracts of water- and salt-soluble proteins (in \% wet weight fish) was determined with BioRad protein assay using gamma globulin as a standard. The analyses were run in triplicate and the mean value \pm SD was calculated. 
Protein carbonyl groups in sarcoplasmic and myofibrillar proteins were detected by DNPH-based Enzyme-Linked Immunosorbent Assay (ELISA) performed in a 96-well polystyrene plate as described by Cropotova and Rustad (2019) [22]. This is a rapid and highly sensitive plate-based assay technique developed by Buss and co-workers [24] based on derivatization of carbonyl groups with dinitrophenylhydrazine (DNPH) and probing of protein-bound dinitrophenyl (DNP) with an anti-DNP antibody. Carbonyl groups were determined in water- and salt-soluble proteins in quadruplicate by using the indirect ELISA kit STA-310 OxiSelectTM (Cell Biolabs Inc., San Diego, CA, USA), and the average value with standard deviation were calculated. The results were expressed in nmol carbonyls/mg protein.

The color parameters of the sous-vide cooked cod samples were determined instrumentally using a Minolta Chroma meter CR-400 (Konica-Minolta, Osaka, Japan). Before performing the measurements, the instrument was calibrated with the instrument standard white plate. Measurements of color parameters were conducted on preselected locations of each cod sample at room temperature. The data were recorded in color coordinates of $\mathrm{L}^{*}$ (lightness, black $=0$, white $=100$ ), $\mathrm{a}^{*}$ (redness $>0$, greenness $<$ 0 ), and $b^{*}$ (yellowness, $b^{*}>0$, blue $<0$ ) according to the Commission Internationale de l'Éclairage (CIE) Lab scale. Color parameters were read three times on each sample and the average with standard deviation was calculated.

Fluorescence measurements were carried out using a pushbroom hyperspectral camera (VNIR-1024, Norsk Elektro Optikk, Skedsmokorset, Norway) operating in the spectral range from $410-990 \mathrm{~nm}$ with a spatial resolution of $0.28 \mathrm{~mm}$ across-track and $0.48 \mathrm{~mm}$ along track and a spectral resolution of $2.7 \mathrm{~nm}$. A focused LED UV line light was used for the excitation with a center wavelength of $365 \mathrm{~nm}$ (Metaphase UL-LL409-UV365-24) and the emission was recorded at wavelengths higher than $400 \mathrm{~nm}$. The camera was fitted with a lens focused at $1000 \mathrm{~mm}$, mounted $1020 \mathrm{~mm}$ above the conveyor belt carrying the samples to be imaged. Three-dimensional hyperspectral image cubes, built line by line, were obtained by running the conveyor belt at a speed of $1 \mathrm{~cm} / \mathrm{s}$. The fluorescence data were corrected for height variations of the samples by dividing fluorescence intensity at each wavelength by the peak value of each spectrum.

Diffuse reflectance measurements were performed using a VNIR-640 imaging camera (Norsk Elektro Optikk, Skedsmokorset, Norway) with a spatial resolution of about $0.5 \times 0.5 \mathrm{~mm}$ and a spectral resolution of approximately $10 \mathrm{~nm}$, within the spectral range of $430-1000 \mathrm{~nm}$. The camera was mounted $1020 \mathrm{~mm}$ above a conveyor belt carrying the samples at a speed of $40 \mathrm{~cm} / \mathrm{s}$. The samples were illuminated with a custom-made light source, which consists of 14 halogen bulbs (50 W) mounted inside a box made of $10 \mathrm{~mm}$ thick high-density polytetrafluoroethylene (PTFE, also known as Teflon) plates [25].

\subsection{Data Analysis}

Multiple regression analysis was performed to determine the relationships between heat-induced changes and storage and cooking conditions. Analysis of variance (ANOVA) and Tukey's Honestly Significant Difference (HSD) post-hoc tests were performed in the R software, and were used to test differences between sample means, which were considered significant at $p<0.05$. Univariate correlations among the spectroscopic data and traditional parameters were evaluated by the Pearson coefficient. Principal Components Analysis (PCA) was applied on fluorescence data to investigate the ability of these measurements to separate between the samples as a function of cooking and storage conditions.

Partial Least Square Regression (PLSR) and Support Vector Machine Regression (SVMR) models were used to predict cooking conditions and storage times from the spectroscopic data [26-28]. The discriminant ability of each spectral dataset was determined by applying Partial Least Square Discriminant Analysis (PLS-DA) and Support Vector Machine Classification (SVMC) models [28,29]. All the classification and the prediction models developed in this study were validated using a crossvalidation procedure. The prediction and classification models were performed by using the PLS-Toolbox 
v.8.5 (Eigenvector Research) for MATLAB R2018a. The regions of interest were selected manually at the image center for each sample and the average spectral data were generated from the images. The extraction of data was performed in IDL 8.6 (L3Harris Technologies, Inc.).

\section{Results and Discussion}

Cooking Loss: High cooking loss has a negative impact on sensory perception of fish and other seafood. Our results showed that the cooking loss generally increased $(R=0.88, p<0.05)$ both with increasing cooking temperature and cooking time (Figure 1A). The increase in cooking loss with increasing thermal load was previously reported in several studies and explained by protein denaturation and loss of water holding capacity $[5,9,30]$. However, the cooking loss levels in our study seem to be higher than those reported in literature $[5,9,14,30]$. For example, in the present study, the mean cooking loss value of cod samples cooked at $80{ }^{\circ} \mathrm{C}$ for 10 min exceeded $15 \%$. This might be because the fish used in our study was still in pre-rigor, or at least in the early stage of rigor mortis $(<24 \mathrm{~h}$ post-slaughter) while the fish used in the other studies were in rigor state when the samples were heat-treated [10]. Regardless of cooking time, the cooking loss was significantly higher for the cod fillets cooked at 70 and $80^{\circ} \mathrm{C}$ than for those cooked at 50 and $60^{\circ} \mathrm{C}$, while differences in cooking loss between the samples cooked at 50 and $60^{\circ} \mathrm{C}$ and between those cooked at 70 and $80{ }^{\circ} \mathrm{C}$ were not significant. PCA applied to the cooking loss data showed a good separation between the samples as a function of both cooking temperature (according to the PC1) and cooking time (according to the PC2) (Supplementary data S1).
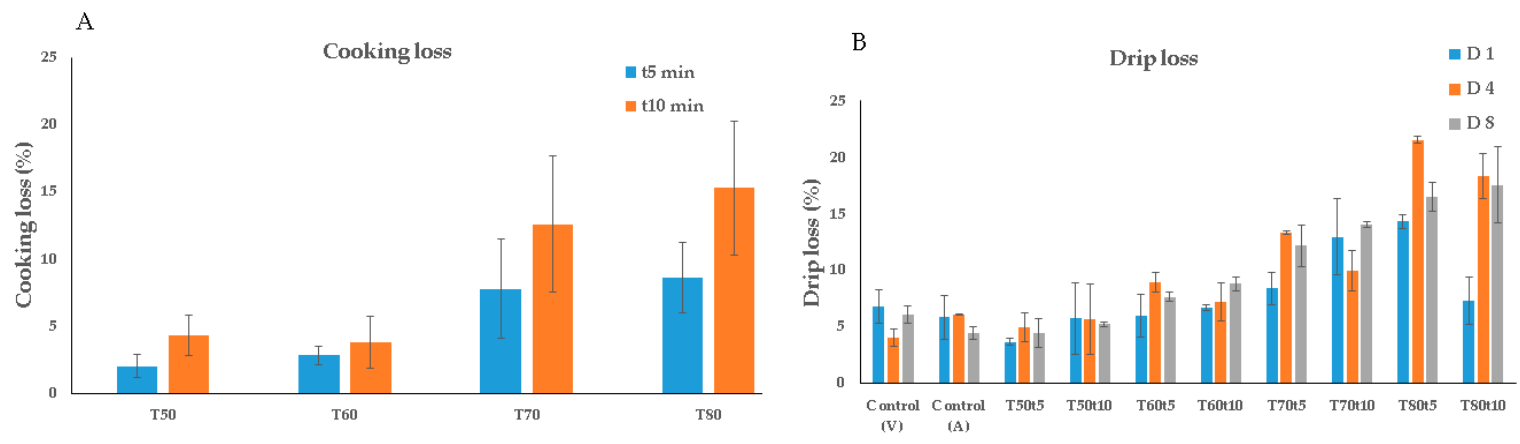

Figure 1. Cooking loss (A) and drip loss (B) obtained on the cod samples as a function of cooking temperature; $\mathrm{T}$, cooking time; $\mathrm{t}$, and storage days; D (V; vacuum-packed samples, A; air-packed samples).

Drip Loss: In the present study, drip loss of untreated cod samples was significantly lower $(p<0.05)$ compared to the drip loss of samples subjected to heat treatment at 70 and $80^{\circ} \mathrm{C}$ for both 5 and $10 \mathrm{~min}$ (Figure 1B). This tendency suggests that a higher thermal load more strongly affects the integrity of the myofibrillar network of cod muscle due to severe denaturation of myofibrils, thus decreasing the water holding capacity of the fish [14]. However, no significant variation was found between the cod loins cooked at $50{ }^{\circ} \mathrm{C}$ for 5 and $10 \mathrm{~min}$ and uncooked samples.

Texture Parameters: A general trend of decreased hardness was observed with storage time (Supplementary data S2), in agreement with other studies [14]. The decrease in hardness was attributed to alteration in muscle structure such as changes in myofibrillar proteins and connective tissue as well as activity of autolytic enzymes [2,31,32]. Regarding the treated samples, significantly $(p<0.05)$ higher hardness values were observed for the samples cooked at $50{ }^{\circ} \mathrm{C}$ compared to the hardness of the samples cooked at the other temperatures $\left(60,70,80^{\circ} \mathrm{C}\right)$. Significantly higher hardness values were observed for the samples cooked for five min compared to those cooked for $10 \mathrm{~min}$, while significant differences were only found among the samples stored for one and four days. A similar trend was observed for the springiness and chewiness parameters. The cohesiveness, which represents the force that holds the integrity of fish structure and prevents it from gaping, was significantly lower 
for the samples cooked at $80{ }^{\circ} \mathrm{C}$. The resilience was significantly affected by both storage time and cooking conditions (temperature and time). Indeed, significantly $(p<0.05)$ higher resilience values were observed for the samples cooked at $50{ }^{\circ} \mathrm{C}$ and for the samples cooked for five minutes than the resilience values of those cooked at 70 and $80^{\circ} \mathrm{C}$ and the samples cooked for $10 \mathrm{~min}$, respectively.

Protein Solubility: The total amount of extracted sarcoplasmic (water-soluble) and myofibrillar (salt-soluble) proteins decreased significantly $(p<0.05)$ after the sous-vide cooking of cod loins compared to untreated fish samples (Supplementary data S3). This reduction indicated heat denaturation and aggregation of these proteins. However, the solubility was neither affected by cooking temperature, nor duration of cooking, since no significant difference between the samples cooked at 50, 60, 70 and $80^{\circ} \mathrm{C}$ for 5 and $10 \mathrm{~min}$, was found. A significant correlation $(\mathrm{R}=0.65, p=0.05)$ was observed between solubility of myofibrillar proteins and drip loss in sous-vide cooked cod samples. Considering that the myofibrillar network is generally responsible for holding water inside the fish muscle [23], we suggest that the decrease in solubility of salt-soluble proteins in the present study contributed to increased drip loss due to thermal denaturation and aggregation of myofibrils [14].

Protein Oxidation: Oxidation is one of the most important quality deterioration processes in muscle foods. Lipid oxidation has been widely investigated, while less attention has been paid to protein oxidation and other oxidative damages. Although oxidation products can be generated from the other compounds in cod (proteins, carbohydrates, etc.), protein oxidation is most likely the dominant pathway in this lean fish. The total carbonyl content increased significantly $(p<0.05)$ both in sarcoplasmic and myofibrillar proteins of sous-vide cooked cod samples compared to uncooked samples (Figure 2). This increase can be explained by the interaction of proteins with various pro-oxidants (free iron, myoglobin, etc.) released from heat-disrupted cells during heat treatment, as well as lipid oxidation products formed during storage of the fish. According to earlier investigations [33], thermal load disturbed the integrity of the fish muscle structure through cell rupture, leading to further oxidation reactions between unsaturated fatty acids, heme pigments (myoglobin) and other pro-oxidants free iron, etc.). The oxidized lipids reacted further with proteins, resulting in their carbonylation. However, cod samples cooked at 50 and $60{ }^{\circ} \mathrm{C}$ had significantly higher $(p<0.05)$ carbonyl content in sarcoplasmic proteins compared to fish samples cooked at 70 and $80^{\circ} \mathrm{C}$. This tendency can be explained by thermal inactivation of prooxidative endogenous enzymes that increase oxidation of fish [33].
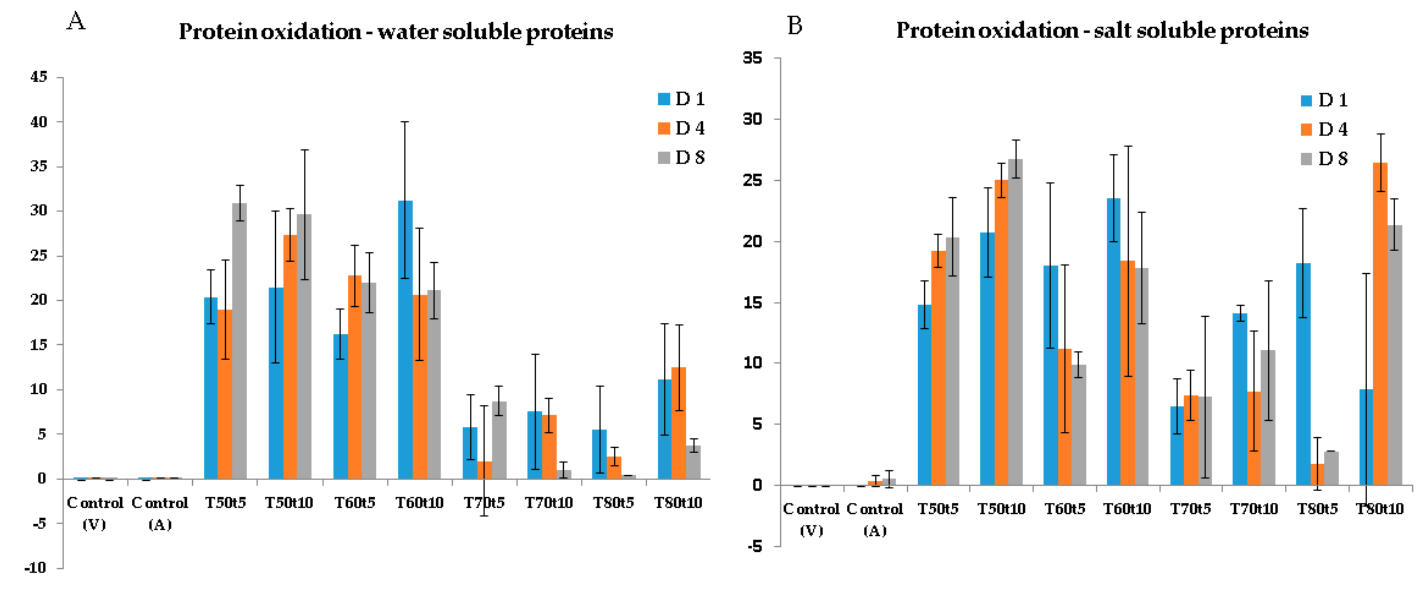

Figure 2. Total carbonyls in sarcoplasmic (A) and myofibrillar proteins (B), obtained on the cod samples as a function of cooking temperature; $\mathrm{T}$, cooking time; $\mathrm{t}$, and storage days; $\mathrm{D}$ (V; vacuum-packed samples, A; air-packed samples).

Changes in Color: The lightness ( $L^{*}$-value) of the sous-vide cooked cod increased significantly $(p<0.05)$ along with a gradual decrease in redness ( $\mathrm{a}^{*}$-values) during the storage period (Figure $\left.3 \mathrm{~A}, \mathrm{~B}\right)$ compared to the color parameters of untreated cod samples. These results are in agreement with the previous study of Cropotova and others [14] performed on sous-vide cooked Atlantic mackerel. 
A possible explanation for the increased lightness and consecutively decreased redness of cod flesh may be denaturation and aggregation of heme-proteins [14]. It should be mentioned that modifications of optical characteristics of the muscle tissue, induced by the application of high temperatures, as will be shown later, can also contribute to the observed changes in color. A large variation in yellowness ( $b^{*}$-value) was observed during storage of sous-vide cooked cod samples (Figure $3 C$ ). The variation in yellowness could probably be due to accumulation of lipid-protein oxidation products, including the ones formed from the interaction between aldehyde groups generated during oxidation of lipids with free amino groups of phospholipids and proteins [33]. Most probably, thermal treatment caused rupture of the cell membranes of adipocytes, thereby liberating lipid oxidation products that further came in contact with proteins leading to protein oxidation and change in color of the cod flesh. This hypothesis is supported by a significant correlation between $b^{*}$-value and amount of protein carbonyls generated in both sarcoplasmic $(\mathrm{R}=-80, p<0.05)$ and myofibrillar proteins $(\mathrm{R}=-0.69, p<0.05)$.

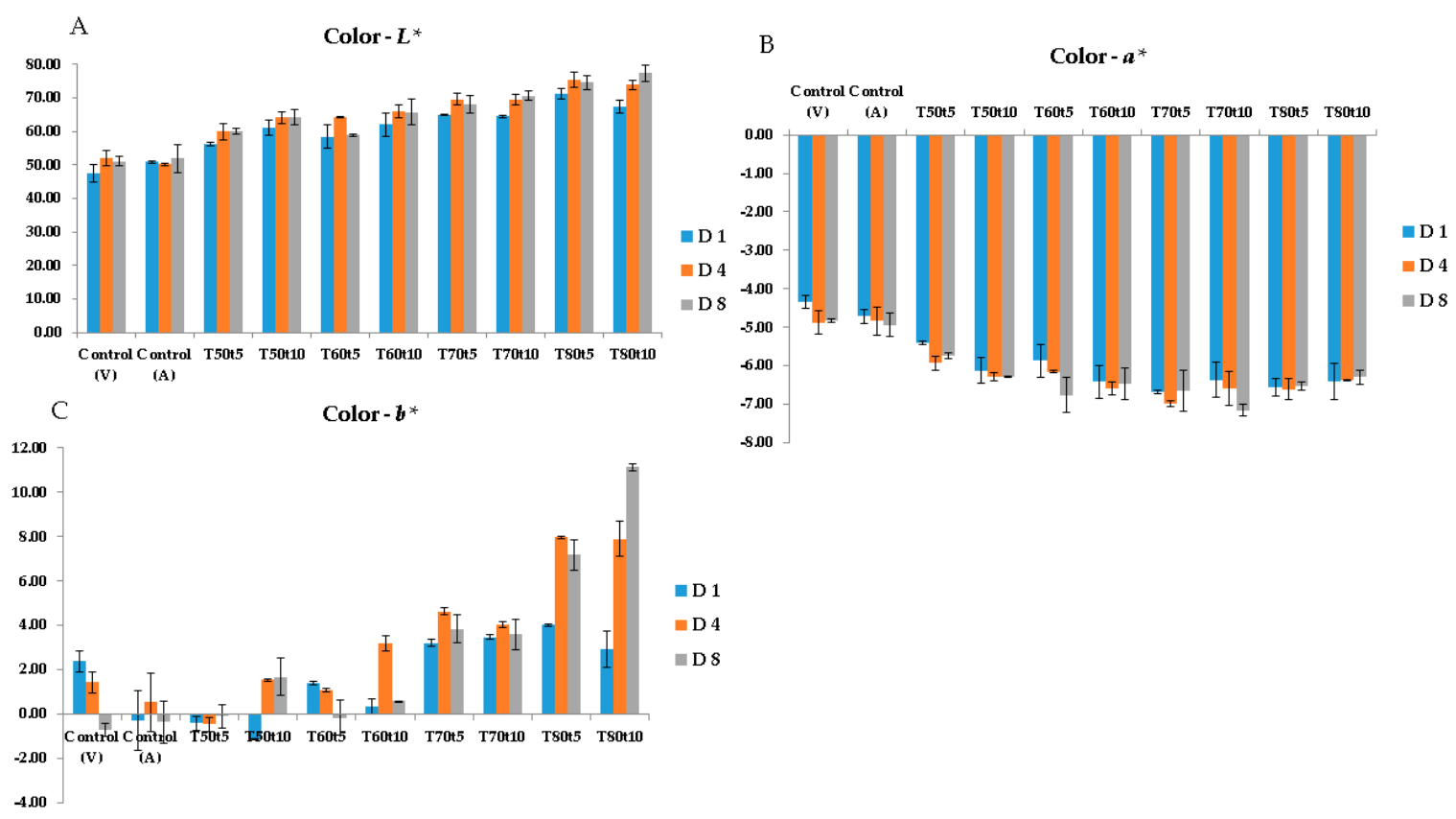

Figure 3. Color parameters: lightness (A), redness (B), and yellowness (C), obtained on the cod samples as a function of cooking temperature; $\mathrm{T}$, cooking time; $\mathrm{t}$, and storage days; D (V; vacuum-packed samples, A; air-packed samples).

A PCA was carried out on the mean values of all traditional measurements, including protein oxidation, protein solubility, texture, color, and drip loss data (Supplementary data S4). The first two principal components accounted for $62.29 \%$ of the total variance $(41.83 \%$ for the PC1 and $20.46 \%$ for the PC2). The PCA score plot showed a clear separation of the control group from the cooked cod samples. Moreover, the cod samples cooked at low temperatures $\left(50\right.$ and $\left.60^{\circ} \mathrm{C}\right)$ were well separated from those cooked at high temperatures $\left(70\right.$ and $\left.80^{\circ} \mathrm{C}\right)$. The loading of the PCA revealed that the most influencing parameter on the control group was the proteins solubility, positively correlated with the PC1. The low-temperature cooked samples were mostly affected by protein oxidation and cohesiveness, positively correlated with the PC2, while the high-temperature cooked samples were mainly influenced by drip loss and $L^{*}$ color, negatively correlated with the PC2.

Fluorescence Spectra: Compared to other spectroscopic techniques, the fluorescence spectroscopy is very sensitive to changes in the local molecular environment of fluorophores, such as changes in $\mathrm{pH}$, temperature, polarity, and color [34-36]. Fish can be considered as a multifluorophoric matrix due to their content of several fluorophores, such as aromatic amino acids, nicotinamide adenine dinucleotide (NADH), riboflavin, oxidation products, collagen, among others. 
The Figure 4A shows that both the storage time and packaging type have important impact on fluorescence spectra. Although no shift in the fluorescence maximum peak position was seen, fluorescence emission around $460 \mathrm{~nm}$ seemed to decrease with increasing storage time in both packaging types, and the fluorescence emission of vacuum-packed samples is higher than that of air-packed samples. Previous studies also reported that storage time and packaging type influence fluorescence spectra [37-39]. Figure 4B displays changes in fluorescence spectra as a function of cooking temperature and cooking time. Other studies have shown that heating temperature and time have an important impact on fluorescence spectra $[7,21,40]$. The results show that the impact of time ( 5 and $10 \mathrm{~min}$ ) is clearer at low temperatures $\left(50\right.$ and $\left.60^{\circ} \mathrm{C}\right)$, than at high temperatures $(70$ and $80{ }^{\circ} \mathrm{C}$ ) probably due to a complete denaturation of proteins after cooking at higher temperature. Several studies have shown that the denaturation of proteins in fish and other seafood increases with increasing cooking temperature and time $[14,41]$. The impact of cooking conditions (temperature and time) was studied along with the subsequent storage time, using classical multiple linear regressions. The mean fluorescence emission at $461 \mathrm{~nm}$ was set as the dependent variable (input $\mathrm{Y}$ ), while cooking temperature, cooking time, and storage time were set as independent parameters (inputs $\mathrm{X} 1, \mathrm{X} 2, \mathrm{X} 3$ ), and the following Equation (1) (Supplementary data S5) was derived:

$$
\mathrm{F}=3.64-0.026 \mathrm{~T}-0.048 \mathrm{~d}\left(\mathrm{R}^{2}=0.77\right)
$$

where $\mathrm{F}=$ fluorescence intensity at the maximum emission (arbitrary unit), $\mathrm{T}=$ cooking temperature $\left({ }^{\circ} \mathrm{C}\right), \mathrm{d}=$ duration of chilled storage (day).
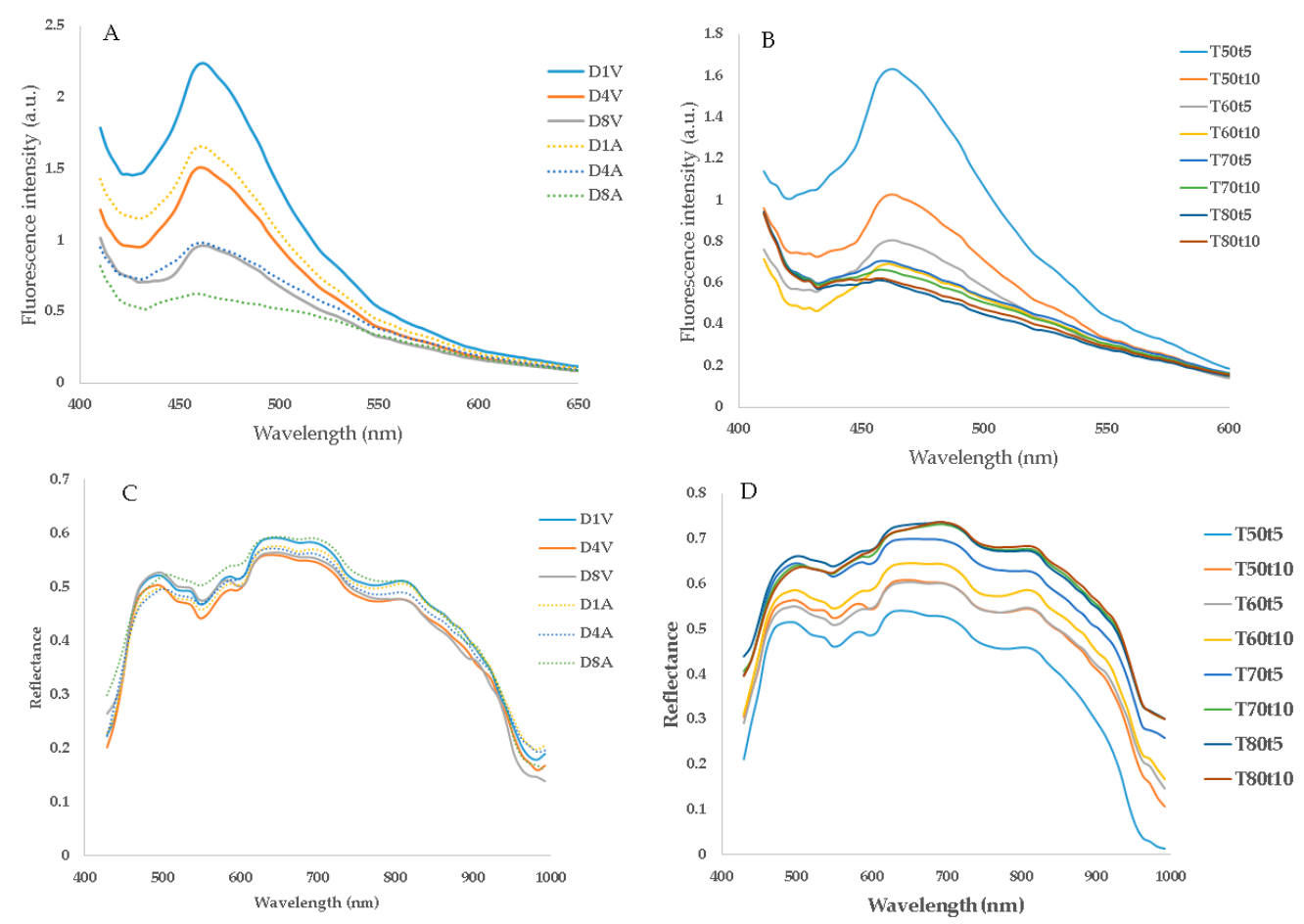

Figure 4. Mean fluorescence (A,B) and diffuse reflectance $(C, D)$ spectra of the control (A and C) and the heat treated samples (B and D), obtained as a function of storage days (D), packaging types (V; vacuum-packed samples, A; air-packed samples), and cooking conditions; cooking temperature; T, cooking time; $\mathrm{t}$.

The results show that increasing both cooking temperature and storage time induced a decrease in fluorescence emission, while the contribution of cooking time was not significant. This decrease can be due to an increase in protein denaturation and a decrease in collagen content, since fluorescence around this emission wavelength (around $460 \mathrm{~nm}$ ) can be attributed to collagen [42,43]. Recently, 
Cropotova and coresearchers noticed a significant decrease in collagen content of sous-vide cooked mackerel during chilled storage [2]. Besides the changes in fluorescence intensity, a blue shift in the maximum peak position of about $4 \mathrm{~nm}$ and $6 \mathrm{~nm}$ was observed for the mean spectra of samples cooked at 70 and $80^{\circ} \mathrm{C}$, respectively, compared to the control and low-temperature heated samples, which might indicate a less polar environment for the samples heated at high temperatures.

Visible Near-Infrared Diffuse Reflectance Spectra: Diffuse reflectance spectra have several advantages, including (among others), the possibility of scanning samples online (on a conveyor belt) when only one surface is available, and illuminating the sample ideally without shadow on the surface or the background [44]. The mean reflectance spectra of cod samples packed with or without vacuum and stored for different times are shown in Figure $4 \mathrm{C}$. The spectra have a similar general trend with small differences in spectral shape and reflectance values. The main peaks in the visible and near infrared parts of the spectra have been attributed to water and different oxidation states of haemoglobin $[25,45,46]$. Figure $4 \mathrm{D}$ shows the mean spectra of cod samples cooked at different temperatures and durations. It can be observed that the samples cooked at the highest temperature have the lowest absorbance value (highest reflectance) and vice versa. These results agree with those reported in previous studies and are explained by changes in optical characteristics, such as absorption and scattering properties, caused mainly by protein denaturation, loss in water binding, and other structural changes $[8,11,12]$. In more detail, the interaction of light with biological tissue is the result of a complex interplay between light absorption and light scattering, representing the possibility of a photon being respectively absorbed and scattered inside the sample. The scattering is associated with the structural and physical properties of the sample, while the absorption is mainly related to the chemical composition and concentration of the various chemical components that absorb light at different wavelengths in different manners. Upon heating, systematic changes in the spectra can be seen, with more scattering and less intense absorption, due to less absorbance of water, proteins, and other organic compounds. More specifically, an increase in cooking temperature causes an increase in scattering particles, as a result of protein denaturation, which in turn decreases absorption from functional groups in water and proteins. These changes and alteration in optical properties, caused by the high temperatures, impacts several physical properties of fish muscle, such as changes in color and texture.

A classical multiple linear regression was carried out to explain the impact of cooking conditions and storage time on diffuse reflectance spectra, and the following model (2) (Supplementary data S5) was obtained:

$$
\mathrm{DR}=1.096-0.0064 \mathrm{~T}-0.0078 \mathrm{~d}\left(\mathrm{R}^{2}=0.84\right)
$$

where DR $=$ diffuse reflectance (mean value), $\mathrm{T}=$ cooking temperature $\left({ }^{\circ} \mathrm{C}\right), \mathrm{d}=$ duration of chilled storage (day).

Again, for the fluorescence spectra, the diffuse reflectance spectra were significantly affected by cooking temperature and storage time, while the impact of cooking time was not significant. Indeed, the diffuse reflectance spectra show a small difference between samples cooked for 5 and 10 min when cooking temperature was high. As only two cooking time durations (5 and $10 \mathrm{~min}$ ) were considered in this study, a wider range with a longer time should be tested in future work. The changes induced in the spectra of samples treated thermally were attributed to modifications in the environment of protein structure (especially the secondary structure, due to the denaturation of proteins) and to changes in the state of water [45].

Correlation Between Traditional Measurements and Spectroscopic Results: Pearson's correlations coefficients among the traditional measurements and the spectroscopic data were calculated. The correlations between the measurements were investigated for both the chilled stored samples (control group) and the treated samples as a function of storage time and cooking conditions (cooking temperature and cooking time).

Correlation Between Fluorescence Data and Traditional Measurements: The correlations between fluorescence data and reference measurements of the control samples were first investigated. 
A moderate-to-strong correlation was observed between most reference measurements and fluorescence emission around the wavelengths $450 \mathrm{~nm}$ and $500 \mathrm{~nm}$. For example, high correlations were noticed between fluorescence data around the maximum emission and protein solubility $(R=-0.94)$, $a^{*}$ color parameter $(R=83)$, springiness $(R=82)$, and resilience $(R=81)$, whereas lower correlations were observed with carbonyls in salt-soluble proteins $(R=-75)$ and the other texture and color parameters (with $R$ values varying between 0.65 and 0.79 ). Other studies have also reported correlations between fluorescence measurements and references analysis performed on fish during chilled storage [47], frozen storage [48], or storage under different conditions [31,38]. Subsequently, in our study, the correlation was developed in order to investigate relationship between the fluorescence and reference measurements performed on the heat-treated samples. The results revealed different patterns with varying efficiency according to the fluorescence emission wavelength used for the correlation and the studied reference parameter. For example, the fluorescence intensity around the maximum emission $(461 \mathrm{~nm})$ showed low correlation values with carbonyls in water-soluble proteins $(R=0.64)$, hardness $(R=0.57)$, and chewiness $(R=0.60)$, while a stronger correlation was observed with resilience $(R=0.80)$. However, color parameters, especially the lightness parameter $(R=-0.89)$, as well as the drip loss $(R=-0.79)$, seemed to correlate well with the fluorescence data. The results suggest that the fluorescence spectroscopy can be used to assess changes in fish quality induced by storage time or thermal treatments.

Correlation Between Diffuse Reflectance Data and Traditional Measurements: Relationships between the diffuse reflectance data and the reference measurements, performed on the control cod samples as a function of storage time, were first examined. The results of proteins solubility (water-soluble protein and salt-soluble protein) and protein oxidation (carbonyls in salt-soluble proteins) showed good correlations with diffuse reflectance data. On the contrary to fluorescence data, diffuse reflectance data did not show statistically significant correlations with the texture parameters. These results indicate that combining fluorescence and diffuse reflectance data can give more efficient results, as some traditional parameters seem to be related to fluorescence data while others correlate better with the diffuse reflectance measurements. Recent studies have also suggested that combinations of several spectroscopic techniques can complement each other and enhance the obtained results $[49,50]$. Regarding the treated samples, moderate-to-high correlations were observed between the diffuse reflectance data and some reference measurements (wavelengths around $675 \mathrm{~nm}$ ), such as resilience $(\mathrm{R}=0.74)$, carbonyls in water-soluble proteins $(\mathrm{R}=0.76)$, and drip loss $(\mathrm{R}=-0.90)$. The color parameters, especially $L^{*}(R=-0.96)$ and $b^{*}(R=-0.86)$ displayed high correlations with the diffuse reflectance data, in agreement with previous results [25], showing that diffuse reflectance measurements are highly affected by color of the samples.

Multivariate Analysis and Modelling: Univariate correlations are not always suitable and reliable for studying complex matrices like fish, which could involve possible biological variations in raw materials and undergo different handling during processing. Therefore, multivariate analysis by means of PCA as well as classification and prediction models were applied. In the first step, PCA was applied to the fluorescence and diffuse reflectance datasets. The score plot of the first two principal components (PC1 and PC2) of the PCA applied to the fluorescence spectra is shown in Figure 5A. It can be noted from this plot that the raw fish samples (control group) are well separated from fish samples cooked at high temperatures $\left(70\right.$ and $80^{\circ} \mathrm{C}$ ) or low temperatures $\left(50\right.$ and $\left.60{ }^{\circ} \mathrm{C}\right)$, which in turn are well separated from each other. Similar results were obtained from the PCA applied to the diffuse reflectance spectra (Figure 5C). However, some overlapping can be observed between samples of the different groups, especially between the samples cooked at 50 and $60^{\circ} \mathrm{C}$ and those cooked at 70 and $80^{\circ} \mathrm{C}$, which may be due to variations in the raw material (before cooking) or possible inconsistency during application of thermal treatments. These results are in agreement with those obtained with the PCA carried out on the traditional data (Supplementary data S4). 

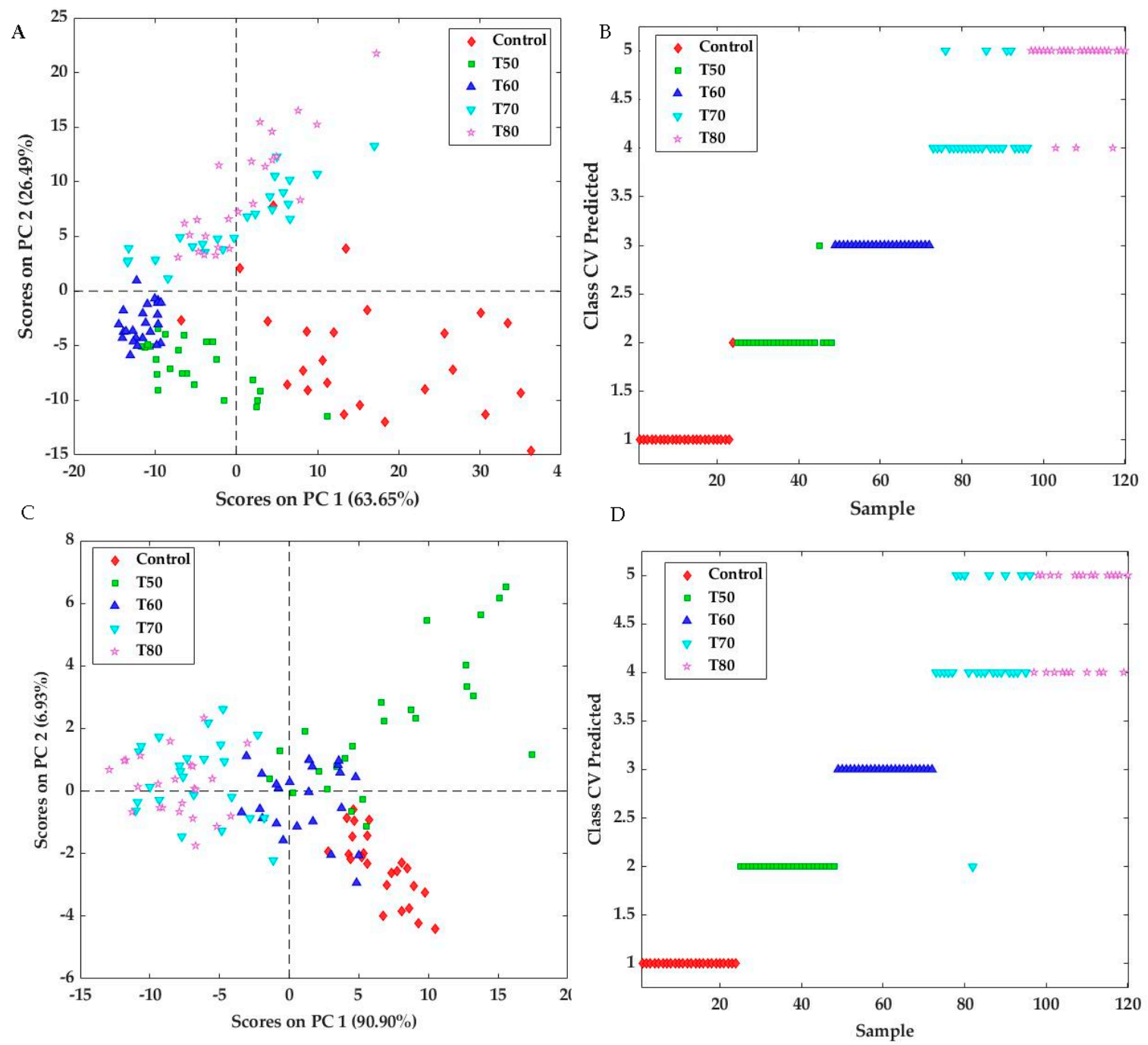

Figure 5. Principal Components Analysis (PCA) (A,C) and predicted cross-validated classes resulted from Support Vector Machine Classification (SVMC) analysis (B,D) applied respectively to the fluorescence $(A, B)$ and the diffuse reflectance $(C, D)$ data, obtained on the control and heat treated cod samples as a function of cooking temperatures (T50, T60, T70, T80).

In the second step, the ability of fluorescence and diffuse reflectance spectra for classifying the cod samples as a function of cooking temperatures was evaluated by means of the PLS-DA and SVMC models. PLS-DA models applied to the fluorescence and diffuse reflectance spectra showed almost a similar performance with overall correct classification rates of $84.16 \%$ and $80 \%$ for the fluorescence and diffuse reflectance models, respectively (Table 2). However, the specificity and sensitivity of the discriminant models applied to fluorescence and diffuse reflectance spectra were different. Indeed, no value lower than 0.80 was obtained for the models based on the fluorescence data, whereas values of 0.76 were observed for the prediction of the class T70 (Table 2), indicating a lower performance of the PLS-DA model based on the diffuse reflectance data compared to the fluorescence results. Overall, the models based on the two spectroscopic data showed high values ( $>0.8)$ of Area Under the Curve (AUC), indicating that these models were promising and robust [28,51]. From the cross-validated predicted classes (Supplementary data S6 and S7) it can be observed that only the samples of the control group are located above the red dotted line, indicating an excellent model for this class, while a lower performance can been seen for the groups T50 and T60, and more overlapping for the classes T70 and T80. 
Table 2. Results of Partial Least Square Discriminant Analysis (PLS-DA) models applied to the fluorescence and diffuse reflectance data sets.

\begin{tabular}{llllll}
\hline & Control & T50 & T60 & T70 & T80 \\
\hline & \multicolumn{5}{c}{ Fluorescence } \\
Sensitivity (Cal) & 0.95 & 0.92 & 0.96 & 0.92 & 0.96 \\
Specificity (Cal) & 1.00 & 0.88 & 0.92 & 0.84 & 0.80 \\
Sensitivity (CV) & 0.96 & 0.87 & 0.96 & 0.87 & 0.83 \\
Specificity (CV) & 1.00 & 0.86 & 0.91 & 0.82 & 0.81 \\
Predicted Control & 23 & 0 & 0 & 0 & 0 \\
Predicted T50 & 0 & 20 & 1 & 0 & 0 \\
Predicted T60 & 0 & 4 & 23 & 0 & 0 \\
Predicted T70 & 0 & 0 & 0 & 18 & 7 \\
Predicted T80 & 1 & 0 & 0 & 6 & 17 \\
& \multicolumn{7}{c}{ Diffuse } & reflectance & \\
Sensitivity (Cal) & 1.00 & 1.00 & 0.96 & 0.88 & 0.96 \\
Specificity (Cal) & 1.00 & 0.95 & 0.93 & 0.76 & 0.83 \\
Sensitivity (CV) & 1.00 & 1.00 & 0.96 & 0.79 & 0.79 \\
Specificity (CV) & 1.00 & 0.94 & 0.90 & 0.76 & 0.83 \\
Predicted Control & 24 & 0 & 0 & 0 & 0 \\
Predicted T50 & 0 & 23 & 2 & 1 & 0 \\
Predicted T60 & 0 & 1 & 22 & 0 & 3 \\
Predicted T70 & 0 & 0 & 1 & 10 & 4 \\
Predicted T80 & 0 & 0 & 0 & 13 & 17 \\
\hline
\end{tabular}

Better results were obtained by application of the SVMC models using a radial basis function kernel, with the best results being observed using the fluorescence spectral data with a correct classification rate of $92.5 \%$ compared to $85.83 \%$ obtained on the diffuse reflectance data (Table 3). Indeed, only nine samples were misclassified using fluorescence data, whereas using diffuse reflectance data, 18 samples were attributed to incorrect classes. The cross validation predicted classes (Figure 5B,D) showed that the samples of the control group and the samples heated at 50 and $60^{\circ} \mathrm{C}$ were well attributed to the corresponding classes. However, most of the samples heated at 70 and $80^{\circ} \mathrm{C}$ were misclassified with each other. The overlapping between the samples heated at 70 and $80^{\circ} \mathrm{C}$ can also be visualized by the predicted probability, which can be obtained by plotting the sample number on the abscissa and the prediction probability for each class on the ordinate (Supplementary data S8 and S9). This may indicate that the spectroscopic techniques used in this study, particularly the diffuse reflectance spectroscopy, can be especially suitable for the classification of samples heated at high $\left(70\right.$ and $\left.80^{\circ} \mathrm{C}\right)$ or low $(50$ and $60^{\circ} \mathrm{C}$ ) temperatures.

In the last step, PLS and SVM regressions were conducted to establish models for predicting cooking temperatures. In this case, the cooking temperature was treated as a dependent variable (Y-variable) that was predicted from the spectroscopic measurements. The models derived from fluorescence and diffuse reflectance spectra pre-treated using Extended Multiplicative Signal Correction (EMSC) and the second derivative are shown in Figure 6. The results demonstrated that the PLSR models yielded satisfactory results with $\mathrm{R}^{2}$ of $0.95,0.91$ and $0.93,0.90$ for calibration and validation data sets of respectively fluorescence and diffuse reflectance spectra (Figure 6A,B). Root Mean Squared Error Cross Validation (RMSECV) was $6.21^{\circ} \mathrm{C}$ and $6.35^{\circ} \mathrm{C}$ for the models applied to fluorescence and diffuse reflectance data, respectively. Better results were obtained by the application of SVM regression models to both datasets (Figure $6 \mathrm{C}, \mathrm{D}$ ). Indeed, very good fits of the models with cross-validation $\mathrm{R}^{2}$ of 0.94, 0.95 and RMSECV of $4.99{ }^{\circ} \mathrm{C}, 4.50{ }^{\circ} \mathrm{C}$ were achieved for the fluorescence and diffuse reflectance data, respectively. Similar results were reported in literature for the prediction of thermal treatments in other seafoods $[1,8]$. 
Table 3. Results of support vector machines classification (SVMC) models applied to the fluorescence and diffuse reflectance data sets.

\begin{tabular}{llllll}
\hline & Control & T50 & T60 & T70 & T80 \\
\hline & \multicolumn{5}{c}{ Fluorescence } \\
Sensitivity (Cal) & 1.00 & 0.96 & 1.00 & 0.91 & 0.87 \\
Specificity (Cal) & 1.00 & 1.00 & 0.99 & 0.97 & 0.98 \\
Sensitivity (CV) & 0.96 & 0.96 & 1.00 & 0.83 & 0.87 \\
Specificity (CV) & 1.00 & 0.99 & 0.99 & 0.97 & 0.96 \\
Predicted Control & 23 & 0 & 0 & 0 & 0 \\
Predicted T50 & 1 & 23 & 0 & 0 & 0 \\
Predicted T60 & 0 & 1 & 24 & 0 & 0 \\
Predicted T70 & 0 & 0 & 0 & 20 & 3 \\
Predicted T80 & 0 & 0 & 0 & 4 & 21 \\
& \multicolumn{7}{c}{ Diffuse reflectance } & \\
Sensitivity (Cal) & 1.00 & 1.00 & 1.00 & 0.75 & 1.00 \\
Specificity (Cal) & 1.00 & 1.00 & 1.00 & 1.00 & 0.94 \\
Sensitivity (CV) & 1.00 & 1.00 & 1.00 & 0.67 & 0.58 \\
Specificity (CV) & 1.00 & 0.99 & 1.00 & 0.90 & 0.93 \\
Predicted Control & 24 & 0 & 0 & 0 & 0 \\
Predicted T50 & 0 & 24 & 0 & 1 & 0 \\
Predicted T60 & 0 & 0 & 24 & 0 & 10 \\
Predicted T70 & 0 & 0 & 0 & 16 & 14 \\
Predicted T80 & 0 & 0 & 0 & 7 & 0 \\
\hline
\end{tabular}

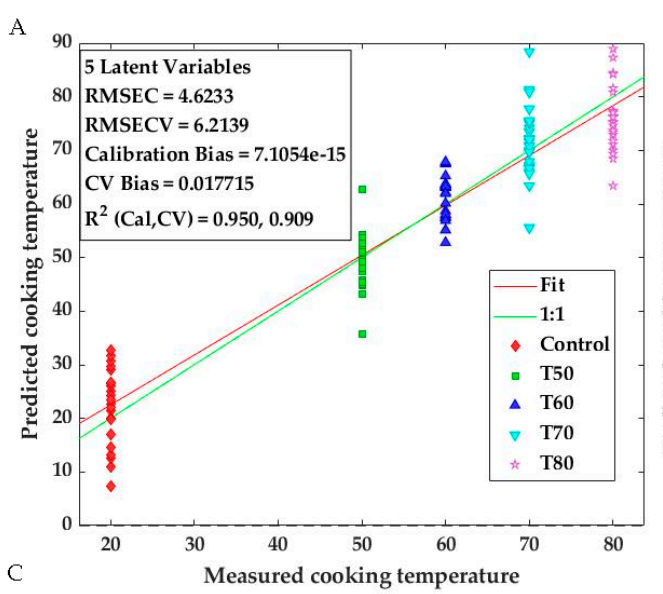

B
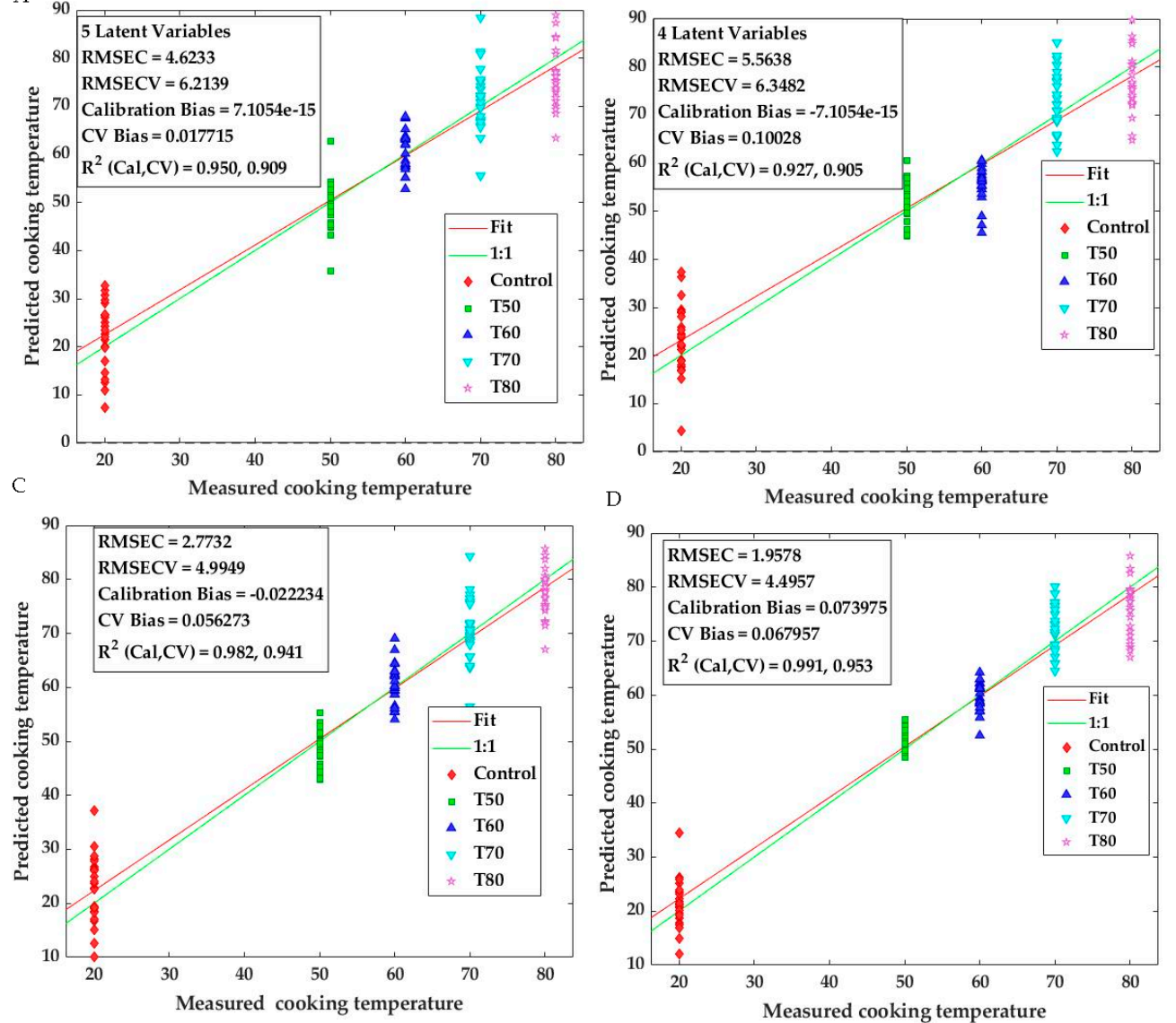

Figure 6. Partial Least Square Regression (PLSR) (A,B) and Support Vector Machine Regression (SVMR) (C,D) results of predicted cooking temperatures, applied respectively to the fluorescence (A and C) and the diffuse reflectance (B and D) data obtained on the control (T20) and heat treated cod samples as a function of cooking temperatures (T50, T60, T70, T80). 
Less accurate results were obtained when the classification and the prediction models were applied to the spectroscopic data used to classify samples and predict cooking time and storage duration. For example, by applying the regressions models to the fluorescence data, the storage time was predicted with $R^{2}$ of $0.82,0.90$ and RMSECV of 1.2 days, 0.89 day for the PLS and SVM regressions, respectively. Regarding the diffuse reflectance data, $R^{2}$ of $0.77,0.88$ and RMSECV of 1.38 days, 0.99 day were obtained for respectively the PLS and SVM regressions models.

\section{Conclusions}

The findings point out that the spectroscopic techniques used in this study enable a differentiation between samples as a function of cooking temperature, whereas less accuracy can be obtained for cooking time and storage time. The support vector machine classification and prediction models used in this study seem to work better than the partial least square models. Fluorescence spectra showed a better performance than diffuse reflectance spectra for samples classification, with an accuracy rate higher than $92 \%$, while a similar performance of the two spectroscopic techniques was observed for the prediction of cooking temperature. However, it should be noted that measurements performed by diffuse reflectance hyperspectral imaging are faster than scanning by fluorescence hyperspectral imaging. The results can be improved by taking the spatial information into consideration in future studies. Moreover, other acquisition modes, such as interactance and transmittance, can be tested in further investigations.

Supplementary Materials: The following are available online at http://www.mdpi.com/1424-8220/20/8/2410/s1, Figure S1: Biplot of the PCA applied to the cooking loss data, obtained on the cod samples as a function of cooking temperature (T50, T60, T70, T80) and cooking time ( $\mathrm{t} 5 \mathrm{~min}, \mathrm{t} 10 \mathrm{~min})$. Table S2: Texture parameters obtained on the cod samples as a function of cooking temperature; T, cooking time; $t$, and storage days; D (V; vacuum-packed samples, A; air-packed samples). No unit for the cohesiveness, springiness, and resilience parameters. Figure S3: Water-soluble proteins (A) and salt-soluble proteins (B), obtained on the cod samples as a function of cooking temperature; $\mathrm{T}$, cooking time; $\mathrm{t}$, and storage days; $\mathrm{D}$ (V; vacuum-packed samples, $\mathrm{A}$; air-packed samples). Figure S4: The PCA applied to the traditional data: T; temperature (T50, T60, T70, T80), V; vacuum-packed samples, A; air-packed samples. Table S5: Multiple linear regression statistics. Figure S6: Cross-validated predicted class resulted from application of PLSDA on the fluorescence data, obtained on the different cod groups: A; Control, B; T50, C; T60, D; T70, E; T80. Figure S7: Cross-validated predicted class resulted from application of PLSDA on the diffuse reflectance data, obtained on the different cod groups: A; Control, B; T50, C; T60, D; T70, E; T80. Figure S8: Prediction probability of the SVMC model applied to the fluorescence data, obtained on the different cod groups: A; Control, B; T50, C; T60, D; T70, E; T80. Figure S9: Prediction probability of the SVMC model applied to the diffuse reflectance data, obtained on the different cod groups: A; Control, B; T50, C; T60, D; T70, E; T80.

Author Contributions: A.H. collected and organized the materials, carried out the experiments and wrote the manuscript. J.C. carried out the experiments and wrote the manuscript. T.R. reviewed the manuscript and made the necessary amendments and corrections. K.H. contributed to the data analysis and reviewed the manuscript. S.-K.L. helped with the data analysis and the revision of the manuscript. H.N. reviewed the manuscript and provided overall guidance. All authors have read and agreed to the published version of the manuscript.

Funding: This research received no external funding.

Conflicts of Interest: The authors declare no conflict of interest.

\section{References}

1. Wold, J.P. On-line and non-destructive measurement of core temperature in heat treated fish cakes by NIR hyperspectral imaging. Innov. Food Sci. Emerg. Technol. 2016, 33, 431-437. [CrossRef]

2. Cropotova, J.; Mozuraityte, R.; Standal, I.B.; Rustad, T. A non-invasive approach to assess texture changes in sous-vide cooked Atlantic mackerel during chilled storage by fluorescence imaging. Food Control. 2018, 92, 216-224. [CrossRef]

3. Llave, Y.; Shibata-Ishiwatari, N.; Watanabe, M.; Fukuoka, M.; Hamada-Sato, N.; Sakai, N. Analysis of the effects of thermal protein denaturation on the quality attributes of sous-vide cooked tuna. J. Food Process. Preserv. 2017, 42, e13347. [CrossRef] 
4. He, S.; Sun, X.; Du, M.; Chen, H.; Tan, M.; Sun, H.; Zhu, B. Effects of muscle protein denaturation and water distribution on the quality of false abalone (Volutharpa ampullacea perryi) during wet heating. J. Food Process. Eng. 2018, 42, e12932. [CrossRef]

5. Skipnes, D.; Johnsen, S.O.; Skåra, T.; Sivertsvik, M.; Lekang, O. Optimization of Heat Processing of Farmed Atlantic Cod (Gadus morhua) Muscle with Respect to Cook Loss, Water Holding Capacity, Color, and Texture. J. Aquat. Food Prod. Technol. 2011, 20, 331-340. [CrossRef]

6. Tavares, W.P.S.; Dong, S.; Bu, X.; Zeng, M.; Zhao, Y. Influence of cooking methods on protein modification and in vitro digestibility of hairtail (Thichiurus lepturus) fillets. LWT 2018, 96, 476-481. [CrossRef]

7. Hu, L.; Ren, S.; Shen, Q.; Ye, X.; Chen, J.; Ling, J. Protein oxidation and proteolysis during roasting and in vitro digestion of fish (Acipenser gueldenstaedtii). J. Sci. Food Agric. 2018, 98, 5344-5351. [CrossRef]

8. Elmasry, G.; Nakauchi, S. Noninvasive sensing of thermal treatments of Japanese seafood products using imaging spectroscopy. Int. J. Food Sci. Technol. 2015, 50, 1960-1971. [CrossRef]

9. Stormo, S.K.; Skipnes, D.; Sone, I.; Skuland, A.; Heia, K.; Skåra, T. Modeling-assisted minimal heat processing of Atlantic cod (Gadus morhua). J. Food Process. Eng. 2017, 40, e12555. [CrossRef]

10. Stormo, S.K.; Skåra, T.; Skipnes, D.; Sone, I.; Carlehög, M.; Heia, K.; Skjelvareid, M.H. In-Pack Surface Pasteurization of Capture-Based, Pre-Rigor Filleted Atlantic Cod (Gadus morhua). J. Aquat. Food Prod. Technol. 2018, 7, 1-12. [CrossRef]

11. Stormo, S.K.; Sivertsen, A.H.; Heia, K.; Skipnes, D. Endpoint temperature of heat-treated surimi can be measured by visible spectroscopy. Food Control. 2012, 26, 92-97. [CrossRef]

12. Skåra, T.; Stormo, S.K.; Skipnes, D.; Kondjoyan, A.; Sivertsen, A.; Gins, G.; Van Derlinden, E.; Valdramidis, V.P.; Van Impe, J.F. Estimation of surface temperature and thermal load in short-time heat treatment of surimi through reflectance spectroscopy and heat transfer modeling. J. Food Eng. 2014, 120, 75-80. [CrossRef]

13. Wang, J.; Tang, J.; Rasco, B.; Sablani, S.S.; Ovissipour, M.; Qu, Z. Kinetics of Quality Changes of Shrimp (Litopenaeus setiferus) During Pasteurization. Food Bioprocess Technol. 2018, 11, 1027-1038. [CrossRef]

14. Cropotova, J.; Mozuraityte, R.; Standal, I.B.; Rustad, T. The influence of cooking parameters and chilled storage time on quality of sous-vide Atlantic mckerel (Scomber scombrus). J. Aquat. Food Prod. Technol. 2019, 28, 1-14. [CrossRef]

15. Cropotova, J.; Mozuraityte, R.; Standal, I.B.; Grøvlen, M.S.; Rustad, T. Superchilled, chilled and frozen storage of Atlantic mackerel (Scomber scombrus) fillets-Changes in texture, drip loss, protein solubility and oxidation. Int. J. Food Sci. Technol. 2019, 54, 2228-2235. [CrossRef]

16. Bland, J.; Bett-Garber, K.; Li, C.H.; Brashear, S.S.; Lea, J.M.; Bechtel, P.J. Comparison of sensory and instrumental methods for the analysis of texture of cooked individually quick frozen and fresh-frozen catfish fillets. Food Sci. Nutr. 2018, 6, 1692-1705. [CrossRef]

17. Li, C.H.; Bland, J.; Bechtel, P.J. Effect of precooking and polyphosphate treatment on the quality of catfish fillets cooked in pouch in boiling water. Int. J. Food Sci. Technol. 2017, 52, 1844-1851. [CrossRef]

18. Yuan, L.; Dang, Q.; Mu, J.; Feng, X.; Gao, R. Mobility and redistribution of waters within bighead carp (Aristichthys nobilis) heat-induced myosin gels. Int. J. Food Prop. 2018, 21, 835-849. [CrossRef]

19. Gao, R.; Feng, X.; Li, W.; Yuan, L.; Ge, J.; Lu, D.; Chen, B.; Yu, G. Changes in properties of white shrimp (Litopenaeus vannamei) protein during thermal denaturation. Food Sci. Biotechnol. 2016, 25, 21-26. [CrossRef]

20. Xia, K.; Xu, W.; Huang, L.; Song, Y.; Zhu, B.-W.; Tan, M. Water dynamics of turbot flesh during frying, boiling, and stewing processes and its relationship with color and texture properties: Low-field NMR and MRI studies. J. Food Process. Preserv. 2017, 42, e13338. [CrossRef]

21. Hu, L.; Ren, S.; Shen, Q.; Chen, J.; Ye, X.; Ling, J. Proteomic study of the effect of different cooking methods on protein oxidation in fish fillets. RSC Adv. 2017, 7, 27496-27505. [CrossRef]

22. Cropotova, J.; Rustad, T. A novel fluorimetric assay for visualization and quantification of protein carbonyls in muscle foods. Food Chem. 2019, 297, 125006. [CrossRef]

23. Hultmann, L.; Rustad, T. Textural Changes During Iced Storage of Salmon (Salmo salar)and Cod (Gadus morhua). J. Aquat. Food Prod. Technol. 2002, 11, 105-123. [CrossRef]

24. Buss, H.; Chan, T.P.; Sluis, K.B.; Domigan, N.M.; Winterbourn, C.C. Protein Carbonyl Measurement by a Sensitive ELISA Method. Free Radic. Biol. Med. 1997, 23, 361-366. [CrossRef]

25. Skjelvareid, M.; Heia, K.; Olsen, S.-H.; Stormo, S.K. Detection of blood in fish muscle by constrained spectral unmixing of hyperspectral images. J. Food Eng. 2017, 212, 252-261. [CrossRef] 
26. Ma, J.; Pu, H.; Sun, D.-W. Predicting intramuscular fat content variations in boiled pork muscles by hyperspectral imaging using a novel spectral pre-processing technique. LWT 2018, 94, 119-128. [CrossRef]

27. Yu, X.; Wang, J.; Wen, S.; Yang, J.; Zhang, F. A deep learning based feature extraction method on hyperspectral images for nondestructive prediction of TVB-N content in Pacific white shrimp (Litopenaeus vannamei). Biosyst. Eng. 2019, 178, 244-255. [CrossRef]

28. Xu, J.; Riccioli, C.; Sun, D.-W. Comparison of hyperspectral imaging and computer vision for automatic differentiation of organically and conventionally farmed salmon. J. Food Eng. 2017, 196, 170-182. [CrossRef]

29. Garrido-Novell, C.; Garrido-Varo, A.; Perez-Marin, D.; Guerrero, J.E. Using spectral and textural data extracted from hyperspectral near infrared spectroscopy imaging to discriminate between processed pork, poultry and fish proteins. Chemom. Intell. Lab. Syst. 2018, 172, 90-99. [CrossRef]

30. Skipnes, D.; Østby, M.L.; Hendrickx, M. A method for characterising cook loss and water holding capacity in heat treated cod (Gadus morhua) muscle. J. Food Eng. 2007, 80, 1078-1085. [CrossRef]

31. Hassoun, A.; Karoui, R. Monitoring changes in whiting (Merlangius merlangus) fillets stored under modified atmosphere packaging by front face fluorescence spectroscopy and instrumental techniques. Food Chem. 2016, 200, 343-353. [CrossRef] [PubMed]

32. Zhao, J.; Li, J.; Wang, J.; Lv, W. Applying Different Methods To Evaluate the Freshness of Large Yellow Croacker (Pseudosciaena crocea) Fillets during Chilled Storage. J. Agric. Food Chem. 2012, 60, 11387-11394. [CrossRef] [PubMed]

33. Cropotova, J.; Mozuraityte, R.; Standal, I.B.; Ojha, S.; Rustad, T.; Tiwari, B. Influence of high-pressure processing on quality attributes of haddock and mackerel minces during frozen storage, and fishcakes prepared thereof. Innov. Food Sci. Emerg. Technol. 2020, 59, 102236. [CrossRef]

34. Hassoun, A.; Sahar, A.; Lakhal, L.; Aït-Kaddour, A. Fluorescence spectroscopy as a rapid and non-destructive method for monitoring quality and authenticity of fish and meat products: Impact of different preservation conditions. LWT 2019, 103, 279-292. [CrossRef]

35. Airado, D.; Skaret, J.; Wold, J.P. Assessment of the Quality Attributes of Cod Caviar Paste by Means of Front-Face Fluorescence Spectroscopy. J. Agric. Food Chem. 2010, 58, 5276-5285. [CrossRef]

36. Shibata, M.; Elmasry, G.; Moriya, K.; Rahman, M.; Miyamoto, Y.; Ito, K.; Nakazawa, N.; Nakauchi, S.; Okazaki, E. Smart technique for accurate monitoring of ATP content in frozen fish fillets using fluorescence fingerprint. LWT 2018, 92, 258-264. [CrossRef]

37. Veberg, A.; Sørheim, O.; Moan, J.; Iani, V.; Juzenas, P.; Nilsen, A.; Wold, J. Measurement of lipid oxidation and porphyrins in high oxygen modified atmosphere and vacuum-packed minced turkey and pork meat by fluorescence spectra and images. Meat Sci. 2006, 73, 511-520. [CrossRef]

38. Hassoun, A.; Karoui, R. Front-face fluorescence spectroscopy coupled with chemometric tools for monitoring fish freshness stored under different refrigerated conditions. Food Control. 2015, 54, 240-249. [CrossRef]

39. Airado, D.; Høy, M.; Skaret, J.; Wold, J.P. From multispectral imaging of autofluorescence to chemical and sensory images of lipid oxidation in cod caviar paste. Talanta 2014, 122, 70-79. [CrossRef]

40. Gatellier, P.; Santé-Lhoutellier, V.; Portanguen, S.; Kondjoyan, A. Use of meat fluorescence emission as a marker of oxidation promoted by cooking. Meat Sci. 2009, 83, 651-656. [CrossRef]

41. Skipnes, D.; Van Der Plancken, I.; Van Loey, A.; Hendrickx, M. Kinetics of heat denaturation of proteins from farmed Atlantic cod (Gadus morhua). J. Food Eng. 2008, 85, 51-58. [CrossRef]

42. Liu, H.; Saito, Y.; Al Riza, D.F.; Kondo, N.; Yang, X.; Han, D. Rapid evaluation of quality deterioration and freshness of beef during low temperature storage using three-dimensional fluorescence spectroscopy. Food Chem. 2019, 287, 369-374. [CrossRef]

43. Egelandsdal, B.; Dingstad, G.; Tøgersen, G.; Lundby, F.; Langsrud, Ø. Autofluorescence quantifies collagen in sausage batters with a large variation in myoglobin content. Meat Sci. 2005, 69, 35-46. [CrossRef]

44. Boldrini, B.; Kessler, W.; Rebner, K.; Kessler, R. Hyperspectral imaging: A review of best practice, performance and pitfalls for inline and online applications. J. Near Infrared Spectrosc. 2012, 20, 438. [CrossRef]

45. Uddin, M.; Okazaki, E.; Ahmad, M.U.; Fukuda, Y.; Tanaka, M. NIR spectroscopy: A non-destructive fast technique to verify heat treatment of fish-meat gel. Food Control. 2006, 17, 660-664. [CrossRef]

46. Wu, D.; Sun, D.-W. Application of visible and near infrared hyperspectral imaging for non-invasively measuring distribution of water-holding capacity in salmon flesh. Talanta 2013, 116, 266-276. [CrossRef] 
47. Risso, S.J.; Crovetto, C.; Ávila, A.; Gutiérrez, M.I. Fluorescence of Extracts from Argentine Hake (Merluccius hubbsi) Muscle and Its Correlation with Quality Indices During Chilled Storage. J. Aquat. Food Prod. Technol. 2017, 28, 1-9. [CrossRef]

48. Bui, M.V.; Rahman, M.; Nakazawa, N.; Okazaki, E.; Nakauchi, S. Visualize the quality of frozen fish using fluorescence imaging aided with excitation-emission matrix. Opt. Express 2018, 26, 22954-22964. [CrossRef]

49. Ma, J.; Sun, D.-W.; Pu, H.; Cheng, J.-H.; Wei, Q. Advanced Techniques for Hyperspectral Imaging in the Food Industry: Principles and Recent Applications. Annu. Rev. Food Sci. Technol. 2019, 10, 197-220. [CrossRef]

50. Ríos-Reina, R.; Callejón, R.M.; Savorani, F.; Amigo, J.M.; Cocchi, M. Data fusion approaches in spectroscopic characterization and classification of PDO wine vinegars. Talanta 2019, 198, 560-572. [CrossRef]

51. McGrath, T.F.; Haughey, S.A.; Patterson, J.; Fauhl-Hassek, C.; Donarski, J.; Alewijn, M.; van Ruth, S.; Elliott, C.T. What are the scientific challenges in moving from targeted to non-targeted methods for food fraud testing and how can they be addressed?-Spectroscopy case study. Trends Food Sci. Technol. 2018, 76, 38-55. [CrossRef]

(C) 2020 by the authors. Licensee MDPI, Basel, Switzerland. This article is an open access article distributed under the terms and conditions of the Creative Commons Attribution (CC BY) license (http://creativecommons.org/licenses/by/4.0/). 